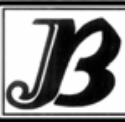

J. bio-sci. 18: 94-98, 2010

ISSN 1023-8654

http://www.banglajol.info/index.php/JBS/index

\title{
MORPHOMETRIC ANALYSIS OF INDIGENOUS, EXOTIC AND CROSSBRED CHICKENS (GALLUS DOMESTICUS L.) IN RAJSHAHI, BANGLADESH
}

\author{
M Saiful Islam* and Ripon Kumar Dutta \\ Department of Zoology, University of Rajshahi, Rajshahi-6205, Bangladesh
}

\begin{abstract}
Context: The quantification of morphometric variations has been regarded as peripheral to the mechanistic study of development of a species. This is now changing because the rapidly advancing knowledge of development in postgenomic biology is creating a need for more refined measurements of the morphometric changes produced by genetic perturbations or treatments.

Objective: To estimate the age at marketable size and body morphometric parameters of indigenous, exotic and crossbred chicken to use such parameters as discriminate variables and to investigate the relationships among the variables of the chicken breeds under study.

Materials and Methods: Six chicken breeds namely an indigenous (non descriptive, Deshi), four exotics as Broiler, Cockerel, Fayoumi and RIR, and a crossbred called Sonali (RIR $3 \times$ Fayoumi + ), were used for the study.

Results: Age and nine morphometric parameters viz., gross weight (GW), blood weight (BW), feather weight (FW), skin weight (SW), body weight after skinning (BWS), visceral weight (VW), offal weight (OW), net edible weight (NEW) and edible ratio (ER), were determined from a total of 30 adult chickens ( 6 breeds 5 replicates each). All the parameters except FW showed significant differences among the breeds $(P<0.01)$. RIR showed the highest values for all parameters except ER, which was the highest in Cockerel $(1.77 \pm 0.23)$ and the lowest in RIR $(1.47 \pm 0.01)$. Association between GW and NEW was statistically significant in Indigenous $(P<0.001)$, Sonali $(P<0.01)$ and all exotics except Broiler $(\mathrm{P}<0.001)$.

Conclusion: Present results indicate that Cockerel, Fayoumi, Indigenous and Sonali chickens are advantageous genotypes as they had higher ER values compared to Broiler and RIR breeds.
\end{abstract}

Keywords: Gallus domesticus, body morphometric traits, net edible weight, edible ratio.

\section{Introduction}

Morphometrics is the quantitative study of morphology, and morphometric data are commonly used to investigate differences among groups of individuals which are genetic or taxonomic in nature (Madsen 1977). Economically important morphometric traits such as body weight, egg production and yield per month are quantitative as well as complex with continuous variability in chickens (Banerjee 1964). Body morphometric parameters are variable on the basis of some factors such as age, sex, climate, nutrition and status of the birds (Banerjee 1992). In the past, studies with chicken body morphometrics by Okada et al. (1988) and Kitalyi (1998), and subsequent studies by Dana and Ogle (2002), Rashid et al. (2005) and Bell et al. (2007) revealed some important results.

Information on the structure of body morphometrics and its various parameters in chickens and other birds are essential for an understanding of migration and dispersal (Warkentin et al. 1990), fertility and reproductive performance (Rahman et al. 1999, Oke and Ihemeson 2009), breeding biology (Villard et al. 2006), growth and development (Bell et al. 2007), egg-size and egg-laying performance (Oke et al. 2007), type and functions between breeds (Olawumni et al. 2008) and selection for phenotypic variability (Rosario et al. 2008). Moreover, body weight and body morphometrics in chickens have been used to differentiate native from exotic (Mulyono et al. 2009) and commercial (Vitorović et al. 2009) breeds, and to establish phenotypic

* Corresponding author; email: saifulzoo@yahoo.co.uk 
correlations among various genetic groups (Yakubu et al. 2009). In addition, a recent surge of interest has led to important advances in formal analysis of variations in shape (i.e. geometric morphometrics) and phylogenetic significance of such changes (Sensen and Hallgrimsson 2009). Here we analyze age and statistical measures of various body morphometrics of the indigenous, exotic and crossbred chickens and report the advantages of the most suitable breeds that are available in and around Rajshahi.

\section{Materials and Methods}

Collection of the chicken breeds: Six adult chicken breeds, one indigenous (non-descriptive, Deshi), four exotics viz. Broiler, Cockerel, Fayoumi and RIR (Rhode Island Red) and one crossbred called Sonali (derived from RIR $\hat{0} \times$ Fayoumi 9 ), were collected at random from six local markets of Rajshahi Metropolitan areas viz. Binodpur, Kazla, Talaimari, Shaheb Bazar, New market and Laxmipur.

Morphometric traits: Age (in month) and body morphometric traits (in g) viz. gross weight (GW), blood weight (BW), feather weight (FW), skin weight (SW), body weight after skinning (BWS), visceral weight (VW) that included crop, small and large intestines and pancreas, offal weight (OW) including weights of heart, liver, kidneys, processed head and gizzard, and net edible weight (NEW), were recorded from five replicates for each breed. Edible ratios (ER) were determined using the formula: $E R=G W / N E W$. Correlations between age vs. GW and BW, and those between GW vs. BW, VW and NEW each were calculated.

Statistical analyses: Mean, standard deviation (SD), analysis of variance (ANOVA), least significant differences (LSD) and co-efficient of correlation values ( $r$ ) were computed using the SPSS (version 11.0 for Windows). Data on age and various body morphometric parameters were subjected to these statistical procedures to detect the significance of the difference between the chicken breeds (Olawunmi et al. 2008).

\section{Results}

Age and body morphometric parameters: Age of the marketable sized chickens differed significantly between breeds $\left(F_{5,24}=721.27, P<0.01\right)$, where RIR showed the highest and Broiler the lowest (Table 1$)$. This is interpretable because RIR is a dual-purpose breed having both meat production and egg laying qualities and therefore it is reared for longer period of time before selling.

Data on GW and NEW are presented in Fig. 1 which reveals that GW vs. NEW was the highest in RIR and the lowest in Fayoumi, with a significant difference between all breeds $\left(F_{5,24}=48.43, P<0.01\right.$, and $F_{5,24}=44.34$, $P<0.01$, respectively for GW and NEW). A similar trend was also recorded for SW, BWS, VW and OW. Similar to GW, BW also showed significant difference between the breeds $\left(F_{5,24}=13.34, P<0.01\right)$, Broiler showing the highest and Indigenous the lowest values (Table 1). Despite genotypic differences and differential consumptions of protein diets at rearing, FW did not differ significantly between breeds $\left(F_{5,24}=2.41, P>0.05\right)$. However, RIR exhibited the highest FW and Indigenous the lowest. SW varied significantly between chicken breeds $\left(F_{5,24}=11.78, P<0.01\right)$ where RIR showed the highest value and Fayoumi the lowest.

Similar to SW, BWS showed significant difference among the breeds $\left(F_{5,24}=49.48, P<0.01\right)$ where RIR also showed the highest and Fayoumi the lowest. VW showed a similar trend as that for SW and BWS, resulting in a significant difference between the breeds $\left(F_{5,24}=30.28, P<0.01\right)$. But unlike $G W, B W, S W$ and $B W S, V W$ was higher in Indigenous than those in Cockerel, thus suggesting an adaptive nature of the Indigenous chickens. OW also showed a significant difference among the breeds $\left(F_{5,24}=69.52, P<0.01\right)$ where $R I R$ exhibited the highest and Fayoumi the lowest. Chicken breeds differed significantly with respect to their ER values $\left(F_{5,24}=4.28, P<0.01\right)$ where Cockerel, Fayoumi, Indigenous and Sonali showed remarkably higher ER compared to that of Broiler and RIR (Fig. 2). This happened due to the higher VW and OW of the latter breeds, even though they had much higher GW values (Fig. 1). 
Associations between various body morphometric parameters: Co-efficient of correlation values shown in Table 2 demonstrate that associations between the age at marketable size and GW of the chickens were significant in RIR and Sonali $(\mathrm{P}<0.05)$, while Broiler and Cockerel each showed negative correlation. Correlation values between the age and BW, on the other hand, were significant for Indigenous and RIR $(P<0.05)$; but Cockerel and Sonali exhibited negative association. GW vs. BW imparted significant correlations in Cockerel and $\mathrm{RIR}(\mathrm{P}<0.01$ and $\mathrm{P}<0.001$, respectively) whereas Broiler showed an insignificant negative value. Only RIR showed a highly significant correlation between GW and VW $(P<0.001)$, but the same correlation showed a negative value in Broiler. Highly significant correlations between GW and NEW $(P<0.001)$ were observed for all breeds except the Broiler, indicating that ' $r$ ' values between morphometric traits are important indicators for breed-specific quality of chickens.

Table 1. Age and some body morphometric parameters recorded in an Indigenous, four exotic and a crossbred adult chickens from

\begin{tabular}{lccccccc}
\multicolumn{7}{c}{ Rajshahi Metropolitan areas } \\
\multicolumn{1}{c}{ Breeds } & Age & BW & FW & SW & BWS & VW & OW \\
\hline Indigenous & $6.2 \pm 1.24^{\mathrm{b}}$ & $24.2 \pm 6.42^{\mathrm{c}}$ & $43.4 \pm 12.20^{\mathrm{c}}$ & $62.2 \pm 25.70^{\mathrm{c}}$ & $558.4 \pm 222.0^{\mathrm{d}}$ & $76.2 \pm 28.8^{\mathrm{c}}$ & $63.8^{\mathrm{a}} \pm 24.9^{\mathrm{b}}$ \\
Broiler & $1.1 \pm 0.07^{\mathrm{d}}$ & $60.4 \pm 6.54^{\mathrm{a}}$ & $72.0 \pm 41.50^{\mathrm{a}}$ & $119.2 \pm 34.60^{\mathrm{b}}$ & $1064.0 \pm 53.2^{\mathrm{b}}$ & $137.2 \pm 41.6^{\mathrm{b}}$ & $75.0 \pm 8.37^{\mathrm{b}}$ \\
Cockerel & $1.6 \pm 0.19^{\mathrm{c}}$ & $34.8 \pm 7.95^{\mathrm{b}}$ & $52.6 \pm 18.80^{\mathrm{b}}$ & $73.8 \pm 29.10^{\mathrm{c}}$ & $583.0 \pm 295.9^{\mathrm{c}}$ & $71.8 \pm 32.8^{\mathrm{c}}$ & $62.6 \pm 18.5^{\mathrm{b}}$ \\
Fayoumi & $1.9 \pm 1.19^{\mathrm{c}}$ & $25.4 \pm 6.46^{\mathrm{c}}$ & $56.4 \pm 7.130^{\mathrm{b}}$ & $53.2 \pm 10.80^{\mathrm{d}}$ & $463.6 \pm 99.4^{\mathrm{f}}$ & $49.6 \pm 10.9^{\mathrm{d}}$ & $49.0 \pm 10.0^{\mathrm{c}}$ \\
RIR & $18.9 \pm 0.61^{\mathrm{a}}$ & $55.8 \pm 9.09^{\mathrm{a}}$ & $79.4 \pm 10.40^{\mathrm{a}}$ & $147.6 \pm 26.90^{\mathrm{a}}$ & $2250.2 \pm 377.0^{\mathrm{a}}$ & $245.4 \pm 40.6^{\mathrm{a}}$ & $273.2 \pm 45.6^{\mathrm{a}}$ \\
Sonali & $1.8 \pm 1.16^{\mathrm{c}}$ & $26.8 \pm 2.99^{\mathrm{c}}$ & $49.4 \pm 5.98^{\mathrm{b}}$ & $60.8 \pm 13.60^{\mathrm{c}}$ & $488.8 \pm 49.4^{\mathrm{e}}$ & $56.8 \pm 12.8^{\mathrm{d}}$ & $51.0 \pm 9.05^{\mathrm{c}}$ \\
\hline
\end{tabular}

BW= Blood wt.; FW= Feather wt.; SW= Skin wt.; BWS= Body weight after skinning; VW= Visceral wt.; OW= Offal wt.; Values are mean $\pm S D$ (N=5 for each) with different superscripts for a parameter in the same column differ significantly by LSD $(P<0.05)$

Table 2. Co-efficient of correlation values $(r)$ estimated between different body morphometric parameters in the Indigenous, exotic and crossbred adult chickens ( $N=5$ for each breed) from Rajshahi

\begin{tabular}{lccccc}
\multicolumn{1}{c}{ Breeds } & Age vs. GW & Age vs. BW & GW vs. BW & GW vs. VW & GW vs. NEW \\
\hline Indigenous & $0.780 \mathrm{~ns}$ & $0.903^{*}$ & $0.740 \mathrm{~ns}$ & $0.796 \mathrm{~ns}$ & $0.995^{* * *}$ \\
Broiler & $-0.823 \mathrm{~ns}$ & $0.749 \mathrm{~ns}$ & $-0.859 \mathrm{~ns}$ & $-0.580 \mathrm{~ns}$ & $0.757 \mathrm{~ns}$ \\
Cockerel & $-0.772 \mathrm{~ns}$ & $-0.641 \mathrm{~ns}$ & $0.966^{* *}$ & $0.727 \mathrm{~ns}$ & $0.995^{\star * *}$ \\
Fayoumi & $0.853 \mathrm{~ns}$ & $0.716 \mathrm{~ns}$ & $0.420 \mathrm{~ns}$ & $0.747 \mathrm{~ns}$ & $0.996^{* * *}$ \\
RIR & $0.984^{* *}$ & $0.990^{* *}$ & $0.999^{* * *}$ & $0.997^{* * *}$ & $1.000^{* * *}$ \\
Sonali & $0.914^{*}$ & $-0.268 \mathrm{~ns}$ & $0.013 \mathrm{~ns}$ & $0.571 \mathrm{~ns}$ & $0.975^{* *}$ \\
\hline
\end{tabular}

vs. = versus; $\mathrm{GW}=$ Gross wt.; BW = Blood wt.; VW = Visceral wt; NEW = Net edible weight; $\mathrm{ns}$ = not significant; *

$=P<0.05 ;{ }^{* *}=P<0.01$ and ${ }^{* * *}=P<0.001$

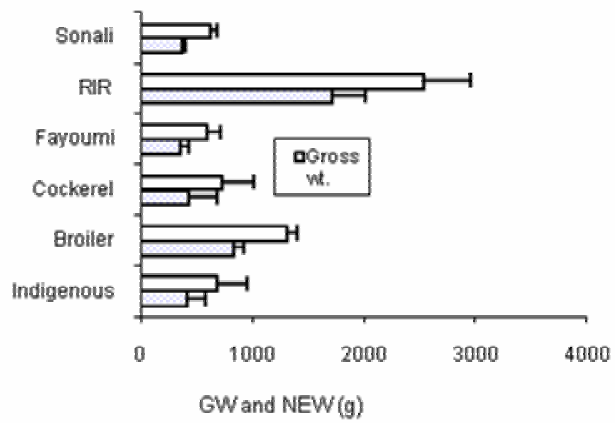

Fig. 1. Comparative GW (gross wt.) and NEW (net edible wt.) in various chicken breeds in Rajshahi

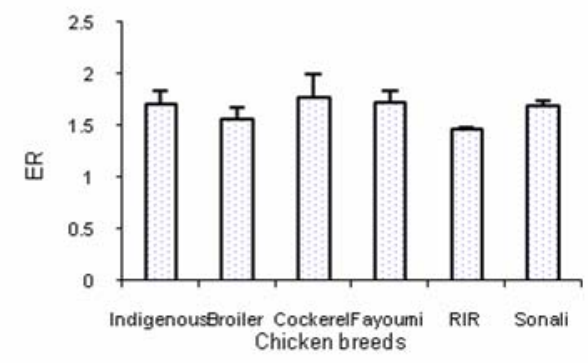

Fig. 2. Estimated ER (edible ratio) in different chicken breeds in Rajshahi

\section{Discussion}

The above results on chicken body morphometrics suggest that breeds like Cockerel, Fayoumi, Indigenous and Sonali would be suitable for consumers, particularly as they attain significantly higher ER values. However, for having some desirable characteristics such as meat flavour, tolerance and resistance to certain 
tropical diseases, being well adjusted to environment and needing less management facilities for rearing, Indigenous would be the most suitable breed (Okada et al. 1988, Rashid et al. 2005, Oke et al. 2007). Similar to the present results, Yakubu et al. (2009) observed correlations between body weight and morphometric traits which were positive and highly significant in three genetic group of chickens viz. normal, frizzle and naked-neck.

The present results conform to those reported by Madsen (1977) who analyzed various morphometric data in 25 strains of chickens. In recent studies body weight and eviscerated carcass, breast and leg yields have been used for discriminating phenotypic variability between Broiler chicken grandparent lines (Rosario et al. 2008) and body size variables were used to distinguish between three breeds of indigenous Indonesian chickens (Mulyono et al. 2009). Vitorović et al. (2009) employed morphometric and mechanical parameters to differentiate three Siberian naked-neck chickens from commercial hybrids, while Yakubu et al. (2009) used body weight and eight body morphometric parameters to differentiate normal, frizzle and naked-neck chickens. In agreement with these findings, ER and VW/OW ratio of the present study can be utilized to discriminate morphometric characters between six chicken breeds under study. Study of the chickens having higher ER and NEW values is important for proper understanding of how to boost production under the prevailing conditions of rearing and their possible inputs for the development of commercial chicken breeds in the country.

Dissimilarities of age at marketable size and morphometric differences observed between breeds of the present study suggest differences in selection goals for chickens. The diversity on these phenotypic characteristics could be considered as distinguishable variables for selection and crosses for improvement of the hybrid line like Sonali (Rashid et al. 2005). Campbell and Lock (1985), Mulyono et al. (2009) and Vitorović et al. (2009) emphasized that the origin, domestication process, selection and crossing success may influence phenotypic variation in body morphometry of the chicken breeds. With special reference to applications in morphometric studies, important results for statistical validity of multivariate analyses now are being made available (Sensen and Hallgrimsson 2009, Yakubu et al. 2009). The rapidly advancing knowledge of development in post-genomic biology is creating a need for more refined measurements of the morphmetric changes produced by genetic perturbations or treatments. This need, in turn, is driving the development of new methods that allow rapid and meaningful integration of molecular, cellular and morphometric data to analyze commercial breeds.

\section{Conclusion}

Nine distinguishing morphometric variables shown in the present study can be used to discriminate commercial chicken breeds in our country. Significantly higher ER values in Cockerel, Fayoumi, Indigenous and Sonali compared to those in Broiler and RIR indicate that the former genotypes would be economically and/or nutritionally potential than the later ones, and therefore, can be recommended as better varieties of chicken suitable for rearing and marketing in Rajshahi. For improving these varieties, however, systematic breed evaluation and artificial insemination, accompanied by effective feeding, management and disease control programmes at farm levels should be emphasized.

Acknowledgements: This forms a part of MSc thesis by RKD. The authors would like to thank numerous poultry sellers and growers in the study areas for their co-operation and sincere help in providing information required for this research. Laboratory technicians also deserve special mention for their assistance in collecting morphometric data. 


\section{References}

Banerjee GC. 1964. A Text Book of Animal Husbandry. (6thedn.). Oxford \& IBH Publishing Co., New Delhi, India. 1079 pp.

Banerjee GC. 1992. Poultry. Mohan Primlani for Oxford \& IBH Publishing Co. Pvt. Ltd. New Delhi, India. 191 pp.

Bell LA, Pitman JC, Patten MA, Wolfe DH, Sherrod SK, Fuhlendorf SD. 2007. Juvenile Lesser Prairie-chicken growth and development in southeastern New Mexico. Wilson J Ornithol 119(3), 386-391. doi:10.1676/05-125.1

Campbell B, Lock E. 1985. A Dictionary of Birds. Buteo Books, Washington, DC, USA.

Dana NA, Ogle B. 2002. Effects of scavenging on diet selection and performance of Rhode Island Red and Fayoumi breeds of chicken offered a choice of energy and or protein feeds. Trop Anim Health Prod 34, 417-429. http://dx.doi:10.1023/A:1020052428067 PMid: 12379060

Kitalyi AJ. 1998. Village Chicken Production Systems in Rural Africa, Household Food Security and Gender Issues. FAO, Rome.

Madsen KS. 1977. A growth curve model for studies in morphometrics. Biometrics 33(4), 659-669. http://dx.doi:10.2307/2529464

Mulyono RH, Sartika T, Nugraha RD. 2009. A study of morphometric-phenotipic characteristic of Indonesian chicken: Kampong, Sentul and Wareng-Tangerang, based on discriminant analysis, Wald-Anderson criteria and Mahalanobis minimum distance. $1^{\text {st }}$ International Seminar on Animal Husbandry 2009. Faculty of Animal Science, Bangor Agricultural University. 278-288 pp.

Okada I, Maeda Y, Hashiguchi T, Hasnath MA, Faruque M, Majid A. 1988. Gene constitution of indigenous chicken in Bangladesh. Jap Poultry Sci 25, 15-26.

Oke UK, Herbert U, Ebuzoeme C, Nwachukwu EN. 2007. Effect of genotype on heamatology of Nigerian local chicken. In: Proceedings of the 32nd Animal Conference of the Nigerian Society of Animal Production. pp 123-125. NSAP Calabar, Nigeria.

Oke UK, Ihemeson C. 2009. Effect of genotype on the morphometric differentiation of the reproductive organs and sperm reserves in the Nigerian local chicken. Livestock Res Rural Dev 22(3), 311-322.

Olawunmi OO, Salako AE, Afuwape AA. 2008. Morphometric differentiation and assessment of function of the Fulani and Yoruba ecotype indigenous chickens of Nigeria. Int J Morphol 26(4), 975-980. http://dx.doi:10.4067/S0717-95022008000400032

Rahman ANMA, Asaduzzaman M, Islam NK, Khan MZI. 1999. Morphometric studies of the ovary and oviduct of high and low egg producing chicken in Bangladesh. Vet Archiv 69(6), 301-308.

Rashid MA, Howlider MAR, Alam J, Rashid A, Kawar MH, Azmal SA. 2005. Effect of dwarfism on reproductive and meat yield parameters of crossbred chicken. Int J Poultry Sci 4(6), 372-377. doi:10.3923/ijps.2005.372.377

Rosario MF, Silva MAN, Coelho AAD, Savino VJM. 2008. Selection of traits in poultry breeding using cluster analysis. Int J Poultry Sci 7(4), 374-378. doi:10.3923/ijps.2008.374.378

Sensen CW, Hallgrimsson B. 2009. Advancement of Imaging in Biology and Medicine. Springer-Verlag, Berlin, Germany. 319 pp. http://dx.doi:10.1007/978-3-540-68993-5

Villard P, Dano S, Bretagnolle V. 2006. Morphometrics and the breeding biology of the Tahiti Petrel Pseudobulweria rostrata. Ibis 148, 285-291.

Vitorović D, Pavlovski Z, Škrbić Z, Lukić M. Petričević V, Adamović I. 2009. Morphometric and mechanical characteristics of leg bones in autochtonous naked neck breeds of chickens in Serbia. Biotechnol Anim Husbandry 25(5-6), 1033-1038.

Warkentin IG, James PC, Oliphant LW. 1990. Body morphometrics, age structure, and partial migration of urban Merlins. American Ornithologists' Union 107(1), 25-34.

Yakubu A, Kuje D, Okpeku M. 2009. Principal components as measures of size and shape in Nigerian indigenous chickens. Thai J Agric Sci 42(3), 167-176 